\title{
La legitimidad de lo político ${ }^{1}$
}

\section{François Terré}

Catedrático del Institut de Droit Comparé

de la Université Panthéon-Assas-Paris II

SUMARIO: I. LA COEXISTENCIA DEL DERECHO Y LA POLÍTICA.- II. LA INVASIÓN DE LA POLÍTICA POR EL DERECHO.- III. LA LEGALIDAD Y LA LEGITIMIDAD DE LO POLÍTICO.

Durante los oscuros días de la ocupación alemana en Francia, la creación literaria y artística, lejos de desaparecer, continúa acrecentándose. Lo mismo ocurriría en el terreno de la Filosofía. En 1943, Sartre publica L'Être et le néant, obra que marcaría el auge del existencialismo francés, aún cuando otros grandes espíritus de la época - como es el caso de Gabriel Marcel- ya habían pasado por la misma etapa. De forma coetánea en el tiempo, Mounier se preparaba para publicar Laffrontement chrétien, en 1944, y el Traité du caractère, en 1946.

En 1943, un emigrante ruso - quien todavía firmara sus manuscritos bajo el nombre de Alexandre Kojevnikof- escribe en el Lot de Gramat, una Esquisse d'une phénoménologie du droit, que no vería la luz si no póstumamente, en 1981, tras su muerte en 1968. Asimismo, en ese mismo periodo, su pluma produciría en ese mismo periodo un ensayo sobre La notion de l'autorité, hoy en día a punto de ser publicada. La trayectoria de quien más tarde sería definitivamente conocido como Kojève es bien conocida en el ambien-

1 Traducción del texto original francés: Dra. $\mathbf{M}^{\mathbf{a}}$ Teresa García-Berrio Hernández, Profesora Contratada Doctora - Facultad de Derecho de la Universidad Complutense de Madrid. 
te cultural francés. A finales de 1919, este autor abandona Rusia en dirección de Alemania en un exilio voluntario que estaría lejos de constituir una renuncia al marxismo-leninismo. Fuertemente atraído por las áreas del espíritu en las que cohabitan, incluso se reencuentran, la Filosofía y la Teología, Kojève dedica su tesis doctoral al estudio de Soloviev. Asimismo, resulta significativa la atención que durante esos años este autor procuraría a la religión, tanto en Oriente como en Occidente, con especial interés al budismo pues, desde su punto de vista, se trataba de una religión atea. La continuación de su carrera, desde 1933 hasta 1939, estará marcada por sus enseñanzas en el seno de l'École Pratique des Hautes Etudes, donde impartiría sus clases en Fenomenología del espíritu ante un auditorio que, con el paso del tiempo, no nos queda más remedio que calificar cuanto menos de "prestigioso": Raymon Aron, Raymond Queneau, Raymond Polin y otros conocidos nombres como Georges Bataille, Roger Caillois, Gaston Fessard...

Para mi intervención de hoy partiré, precisamente, de los análisis y de las reflexiones de Kojève que tienen por objeto de estudio al Derecho. Con este propósito principal, resulta necesario, a mi juicio, que anticipemos dos observaciones previas.

La primera de dichas observaciones se deduce directamente de la lectura de un pasaje de Kojève en el que aborda la cuestión de la Filosofía del Derecho. El Derecho - escribe Kojève en las primeras páginas de su Fenomenología - "todavía no ha encontrado una definición aceptada universalmente y verdaderamente satisfactoria... Así, pues, hablar de una cosa sin poderla definir, es en el fondo como hablar sin saber de lo que se está hablando". Deseoso de ir más allá, Kojève llega a afirmar que no trata, no obstante, de proponer un análisis del Derecho estrictamente fenomenológico. Lo mismo se ha de decir respecto a sus conclusiones, las cuales resultan ser necesariamente incompletas y precisan, en efecto, una serie de prolongaciones de orden metafísico y ontológico del fenómeno descrito. En realidad, este autor está aventurando de este modo uno y otro campo de estudio. 
Indisociablemente ligada a la anterior, una segunda observación se vincula a la constante y permanente cuestión sobre la confrontación de lo jurídico y de lo político que, desde la noche de los tiempos, alimenta a la Filosofía, en general, y a la Filosofía política, en particular. En la época actual, hoy incluso más que nunca, las cuestiones que otorgan sustento a una y otra observación revelan la existencia de vacilaciones del espíritu ligadas al hecho de que el Derecho está por todas partes, incluso allí donde no tiene nada que hacer. Esto explica el que, permitiéndonos aquí la arrogancia de prolongar así el pensamiento de Kojève de forma evidentemente más torpe que la suya - quien sabría cómo superar el pensamiento de Hegel ya que que, a sus ojos, era seguramente el mejor medio de seguir siéndole fiel-, debamos presentar nuestros argumentos en cuatro tiempos: (a) la coexistencia del Derecho y la política; (b) la invasión de la política por el Derecho; (c) la legalidad y la legitimidad de lo político.

\section{LA COEXISTENCIA DEL DERECHO Y LA POLÍTICA}

El Derecho y la política coexisten. Cuando meditamos acerca de la agitada historia de sus relaciones, podríamos decir incluso que se trata de una coexistencia obligada: tanto el uno como la otra se necesitan mutuamente, sienten celos el uno del otro y aspiran a dominar al otro.

Pero, ¿y su disociación?... Este diálogo mutuo no era percibido como tal en la Antigüedad, ni siquiera en el pensamiento de algunos sofistas. Con el transcurso del tiempo, sobre todo con el advenimiento de la Historia contemporánea - enormemente sensible tanto a la fuerza como a la sagacidad de lo político-, se acuerda cada vez más importancia al estudio de las relaciones que median entre el Derecho y la fuerza. Vanamente nos complacemos revalorizando los atractivos que ofrece una sociedad que se rige únicamente por el Derecho y que ignora la fuerza. Vanamente nos esforzamos por encontrar aquello que, con el paso del tiempo, va primero: la fuerza o el Derecho. Lo 
esencial se encuentra en otro lugar e implica la confrontación de dos tesis fundamentales que, una vez hechas las cuentas, resultan ser insuficientes. Pese a ello, debemos examinar necesariamente cada una de ellas.

Según la primera tesis, el Derecho no puede encontrar su fundamento en sí mismo en la medida en que éste se limita a formular reglas y a imponer obligaciones. Desde dicha perspectiva, resulta necesario asentar el poder de coerción del Derecho en una fuerza política externa. Sin embargo, si consideramos implícitamente que sólo una fuerza legítima puede legitimar al Derecho, dicha exterioridad constituiría una trampa puesto que, en ese caso, se debe buscar del lado del Derecho la legitimidad de la fuerza que inspira y fundamenta a su propia legitimidad. Incluso si hiciéramos abstracción de esto último y consideráramos como justo todo lo que quiere la fuerza, nos estaríamos emplazando en una posición filosófica de tipo marxista imposible de sostener, ya que confunde el Ser con el Deber-Ser.

En abierta oposición a esta última concepción encontramos una segunda tesis, a primera vista seductora, favorable a buscar en el Derecho su propia fuerza. Este orden de obligaciones en que consistiría el Derecho, según Kelsen, conlleva en sí su propia fuerza en tanto en cuanto se trata de Derecho. Julien Freund resume de forma excelente este estado de cosas, aventurando que, mientras que la primera tesis sostiene que la fuerza hace la fuerza, la segunda tesis reposa sobre la idea de que el Derecho hace la fuerza o, de manera más inventiva, que éste contiene dicha fuerza en sus propias entrañas. A simple vista, este giro debe evidentemente satisfacer a las gentes deseosas de justicia, puesto que la política, con todos los excesos que le son propios, resultaría ser en cierto modo domesticada. El Derecho lo impregnaría y fundamentaría todo, el Estado se convertiría en su servidor y el aparato político aparecería subordinado al engranaje jurídico. Desde el punto de vista de la armonía social y de la coexistencia de las libertades, este rechazo de lo político resulta ser, pese a todo, negador de la libertad en la medida en que vacía progresivamente el campo propio de lo jurídico para pasar a considerarlo en 
su formalismo extremo y en un espléndido aislamiento de todos los valores que lo inspiran o deberían inspirarlo por la mediación de la política, así como también de todos los valores morales que proceden del propio Derecho; esto último le permitiría librarse de todas las desconfianzas del positivismo jurídico. Existe una plaza eminente para la trascendencia en el Derecho. Ignorar esto último lleva a admitir que regímenes como el nazi sean considerados como sistemas válidos en la medida en que existen.

De la confrontación aquí presentada se puede extraer que la fuerza y el Derecho son "dos nociones conceptualmente autónomas": "la relación entre las dos consistiría en intercambios dialécticos que pueden ser amistosos u hostiles, según las circunstancias" (Julien Freund).

Para ilustrar tal distinción, plenamente asentada en términos políticos e incluso -aunque algunos lo nieguen- jurídicos, la aportación de la Fenomenología de Kojève resulta ser esencial. Este autor cree haber encontrado el modo de aislar y de comprender el fenómeno jurídico. A su juicio, todo fenómeno jurídico implica necesariamente, mediante una interacción entre dos seres humanos, la intervención de una tercera persona imparcial y desinteresada. El que se trate de una interacción entre dos seres humanos excluiría de todo reconocimiento a cualquier relación de derecho directa que pudiera darse entre el hombre y el animal, entre el hombre y los bienes, $o$ incluso entre el ser y el poseer. Pero, prosiguiendo con este razonamiento, para que se manifieste plenamente el fenómeno jurídico a esta interacción se le ha de sumar -0 por lo menos tener vocación de añadírsele- la intervención de una tercera persona imparcial y desinteresada, por ejemplo, de un legislador y, sobre todo, de un juez.

Este personaje imparcial y desinteresado, ¿existe en realidad? ¿Puede llegar incluso a existir algún día? Su necesario desinterés ha de ser comprendido no en relación al propio interés de actuar en beneficio de la sociedad, sino en relación a consideraciones personales de carácter mercantil tan acordes a la estela de utilitarismo de los tiempos modernos. Ahora bien, si este personaje existe, 
ello se debe a que, según un análisis fiel al pensamiento hegeliano, existe en todo hombre un deseo interno de hacer justicia, un placer de juzgar; placer, este último, propiamente jurídico que le es absolutamente personal a cada hombre y que se encuentra inspirado por la propia idea de Justicia. Para Kojève, como para Hegel, el hombre económico tiene como doble un hombre vanidoso que aspira al reconocimiento social como condición para la construcción de la propia conciencia de sí mismo, comenzando por la conciencia de juzgar y continuando con la conciencia de ser juzgado.

Querámoslo o no, el análisis fenomenológico conlleva una prolongación sobre el alcance del Derecho positivo, es decir, del Derecho establecido. Desde esta perspectiva, Kojève no es en absoluto un partidario del Derecho Natural. Tampoco puede ser considerado como iusnaturalista, sino como legalista. A su juicio, la primacía del Derecho positivo no es otra que la primacía del Derecho que existe en acto. Pero si, contrariamente al Derecho positivo, se invoca un Derecho justo, éste se trata de un Derecho en potencia. Así, pues, si cualquier discordancia se manifestara claramente entre el Derecho en acto y el Derecho en potencia, una fuerza inherente a la propia idea de Justicia priva o privará al Derecho positivo de la autoridad que le es necesaria para mantenerse de forma durable.

Tal y como resultan ser caracterizados, tanto lo político como lo jurídico son llamados a repartirse armoniosamente, en función de sus dominantes respectivas, las relaciones sociales que se les otorgan y que han de tratar. Esta repartición de ámbitos ilustra claramente las diferencias de orden fenomenológico que existen entre ellos, sobre todo, en la medida en que lo político reposa esencialmente sobre un tratamiento de relaciones binarias - amigo, enemigo; gobernante, gobernado- sin intervención alguna de una tercera persona imparcial y desinteresada. Que existan leyes relativas a dicho ámbito es muy posible - por poner un ejemplo, la cuestión de la bandera nacionalSin embargo, no nos emplazamos aquí en absoluto en la esfera del Derecho, puesto que, en el presente análisis, el 
ámbito propiamente jurídico es comprendido de una forma mucho más estrecha que lo que constituiría el modo de aproximación habitual de los juristas. Esto explica que en Derecho Internacional Público, rama del Derecho reguladora de las interacciones que median entre Estados soberanos, se tienda a evacuar lo jurídico. Desde esta perspectiva, incluso la noción de soberanía excluiría la posibilidad de una obligación irresistible que proviniese del exterior y, así pues, toda "tercera persona" no dispondría en Derecho Internacional de ningún medio para imponer su intervención a los "justiciables", quienes siempre pueden sustraerse a la misma. A este último razonamiento podríamos contraponer el comportamiento de los Estados neutros, aparentemente "terceros países" imparciales, incluso desinteresados. La posible respuesta a esta cuestión, convincente para algunos aspectos y no así para otros, sería que no se ha de confundir la no-beligerancia con la neutralidad, ya que el no-beligerante, al no ser ni amigo ni enemigo, es por naturaleza un enemigo en potencia.

En Derecho interno, la posibilidad de trazar una línea compartida, y por lo demás empírica, resulta ser todavía más dificultosa. Para Kojève, el Derecho Público tan sólo resultaría ser Derecho en la medida en que estableciera una serie de reglas entre administradores y administrados que permitieran que éstos últimos fueran tratados como personas privadas. En este sentido, no faltan los interrogantes entorno a las tesis de ciertos pesadores históricos que tratan de explicar el desarrollo y el papel de la jurisdicción administrativa en Francia - la administración que se juzga-, pero, sobre todo, acerca de lo que se conoce como el "servicio público a la francesa". Así, pues, en el análisis que efectúa Kojève "allí donde se trata de relaciones de interacción con el propio Estado, no hay elemento jurídico en absoluto". Con más razón resulta ser así cuando se pasa del Derecho administrativo al Derecho constitucional: "En la medida en que la Constitución fija el estatus del Estado y de los ciudadanos, ésta no tiene nada de jurídica. Es una ley puramente política del Estado, es decir, una ley que el gobierno crea como quiere y que éste 
puede cambiar como quiera... Si el ciudadano actúa como ciudadano entonces, por definición, éste no puede entrar en conflicto con el Estado". Pese a la concurrencia de tantas fórmulas - a simple vista paradójicas, excesivas y radicales- el jurista de nuestra época debe especialmente interrogarse, no obstante, acerca de los excesos del todojurídico, sobre todo ante el espectáculo de zonas intermedias respecto a las que el modo de operar del filósofo resultaría ser particularmente esclarecedor y operacional.

\section{LA INVASIÓN DE LA POLÍTICA POR EL DERECHO}

En la época actual, podemos constatar una invasión de la política - en el sentido noble, incluso antiguo, del término- por el Derecho. Ningún obstáculo parece oponerse a este expansionismo particularmente representativo en Occidente, lo cual es debido a un estado de espíritu optimista, beatamente ligado al prestigio de la ley. Los especialistas en Derecho comparado hace tiempo que se dieron cuenta de que esta invasión —colonización, quizás- se produce a través de dos vías diferentes: el juez, por un lado, y la regla de Derecho, por otro. Así, pues, en la órbita americana, el "judge made law" domina la jerarquía de normas, lo que puede llegar a confundir demasiado a menudo Estado de Derecho con sociedad contenciosa. Nadie ignora la plaza excesiva que ocupan los lawyers en la sociedad americana y, a pesar de ello, se desconoce por completo que dicha omnipresencia, fuente de lentitud y de excesivo coste, ha resultado ser enormemente beneficiosa para los Estados Unidos. Por otra parte, allí donde prevalece la regla y no así la decisión judicial —en definitiva, en todo el continente europeo y no únicamente en Francia-, "Derecho y pasión por el Derecho" (Jean Carbonnier) gobiernan e inspiran de forma absoluta el conjunto del cuerpo social: decretos-leyes, circulares, órdenes ministeriales, recomendaciones, directivas, diligencias normales, etc. Desde hace tiempo se viene denunciando, en vano, esta inflación de producción legislativa. 
Sin que pretendamos abarcar de forma completa este inmenso ámbito de estudio, trataremos de mostrar aquí cómo, a través de las dos formas principales que se adoptan, este movimiento lesiona profundamente a la política y, como contrapunto, también al Derecho. Dicho con otras palabras, aquí se tratarán dos cuestiones, a raíz de los dos sentidos que se le atribuyen al término Derecho - sentido objetivo y sentido subjetivo-: por un lado, del encantamiento del Estado de Derecho y, por otro, de la ideología de los Derechos Humanos.

La encantamiento del Estado de Derecho ilustra brillantemente estos movimientos hacia la deriva; hasta tal punto resulta ser así que, con bastante frecuencia, se duda acerca de la ortografía de dicha expresión: ¿se ha de escribir en mayúsculas o minúsculas, en singular o plural?... Un gran conocedor de la cuestión, el profesor Jacques Chevallier, resume perfectamente la situación del siguiente modo: "el Estado de Derecho es presentado como un valor en sí mismo, respecto del cual ningún compromiso resulta posible de establecerse; ese término cubre múltiples significados, ampliamente contradictorios entre sí, y se presenta como una noción difusa y a geometría variable; por último, su incorporación al discurso político le confiere efectos de legitimación. El Estado de Derecho aparece, por tanto, como un auténtico mito cuyo alcance no tiene como equivalente más que la imprecisión..."2.

En Derecho constitucional, se asiste a una manifestación evidente de esta expansión. En 1958, el Conseil constitutionnel, fundamentalmente inspirado por el deseo de evitar, en el momento de promulgación de las leyes, una invasión del poder legislativo sobre el poder reglamentario - cosa que finalmente se abstuvo de realizar-, se ha consagrado a limitar a los poderes del Parlamento respecto a lo que en Derecho francés estipula el llamado "bloque de constitucionalidad", formado por los Preámbulos de las Constituciones de la República francesa, la Declaración de

2 Chevallier, Jacques, L'État de droit, $2^{\mathrm{a}}$ ed., París, Domat-Montchrétien, 1994, p. 143. 
Derechos del Hombre y del Ciudadano de 1789 y los principios fundamentales consagrados en las leyes de la República, respectivamente. Desde el preciso instante en que, en 1971, el Conseil se atribuye dicho poder —con posterioridad amplificado de múltiples maneras-, un proceso de constitucionalización del Derecho ha entrevisto, con frecuencia de forma excesiva, la necesidad de libertad de acción que ha se le ha de reconocer a los gobernantes. Pretendiendo recibirlo todo de un Derecho constitucional puntilloso y en ocasiones artificial, vamos en contra de los valores y de los principios que lo inspiran. Y como resulta ser con frecuencia lamentable que una interpretación rigorista de la Constitución frene la acción política, el único remedio a adoptar consistiría entonces en proceder a modificarla en un sentido liberal, de forma que junto a las inestabilidades ministeriales y legislativas del pasado se le añada ahora la inestabilidad constitucional.

Este estado de desequilibrio por atteintee a lo político se revela también en la evolución del Derecho judicial francés, fuertemente sacudido en términos de poderes y de autoridades. Un ascenso de revindicaciones sindicales, que tratan de hacer resurgir a su manera el corporativismo de los Parlamentos de la antigua Francia, se ha desarrollado incesantemente a lo largo de la V República. Este fenómeno ha sido desarrollado hasta tan elevado nivel que, la idea misma de "cortar el cordón umbilical entre los magistrados del Parquet y el poder político" ha progresado a un mismo ritmo. De no ser así, poco a poco, nos olvidaríamos de que, si bien la independencia de los magistrados está asegurada, constituye una función completamente diferente a ésta la desarrollada por los sustitutos y procuradores, quienes tan sólo pueden ser los agentes del poder ejecutivo en el seno de los tribunales.

Por otra parte, la Autoridad judicial, tal y como ha sido heredada de la historia de la democracia, no puede procurarse una legitimidad tal y como se entiende en Francia. Nadie lo ha dicho mejor que Jean Foyer, Ministro de Justicia desde 1962 hasta 1967: "De la larga historia judicial de Francia, una noción destaca. Ésta consiste en la necesidad 
de una adhesión suficiente de los jueces al régimen político y a la organización social en la que les corresponde unificar la observación de las leyes. La dimisión de los magistrados monarquistas y católicos, que abandonan sus funciones a comienzos de la III República ya que no se adherían en absoluto a la legislación antirreligiosa de la época, era la única conducta honorable que éstos podían adoptar. Esta se convierte en ejemplo. Nadie debe actuar contra su propia conciencia. Sin embargo, la República no sabría admitir, sin renegar la legitimidad que ésta detenta de la voluntad popular, que sus tribunales ostentan la voluntad general como fracaso y menos aún que los mismos se transforman en auténticos agentes de subversión. El rechazo del poder no dispone de ningún otro significado; en él reside incluso su propia justificación"3.

En términos de jurisdicción política, o teóricamente política, el debate resurge recientemente respecto al tratamiento penal que se le ha de otorgar al Jefe del Estado; esta cuestión revela ampliamente el debate inherente, sobre todo, si seguimos obstinándonos en no considerar el sorteo como un posible modo de designación de los jueces en tales situaciones. Esto mismo se mantiene cuando se pasa del plano de Derecho interno al plano del Derecho internacional, desde la milenaria justicia de los ganadores, de Nuremberg a La Haya, de la Germania a los Balcanes, de la soberanía de los Estado al autoproclamado derecho de la ingerencia selectiva, de Goering a Milosevic, de Spandau a Guantánamo. Donde podemos encontrar aquí ese juez imparcial y desinteresado? ¿En Serbia o quizás en Ruanda? ¿En Tchechenia o en Camboya? ¿En la ONU o en el Departamento de Estado?

Estas cuestiones resultan ser suficientes por sí mismas. Su mera enumeración extiende el horizonte hacia el examen de tantas otras leyes formales que están condenadas a permanecer como tales ya que no pueden constituir la expresión del Derecho. Tal es el caso de la ley protectora de la lengua francesa que rápidamente muestra su incon-

\footnotetext{
${ }^{3}$ Foyer, JeAn, "Un pouvoir refusé”, en Pouvoirs, 1981, p. 29.
} 
sistencia, si no incluso su carácter nocivo, en la Europa comunitaria en materia de etiquetado de los productos; tal es el caso de la singular ley sobre el reconocimiento del genocidio armenio que sobrepasa los poderes del Parlamento y que resulta ser al final bastante criticable en la medida en que silencia tantos otros genocidios cometidos, comenzando por el genocidio producido en un país que durante largo tiempo permanecerá bajo el dominio colonial francés; tal es el caso de las leyes de bioética, al mismo tiempo inútiles y peligrosas, que eluden inevitablemente, en razón de las cosas de la vida y de la ciencia, las cuestiones esenciales, etc.

Las imprecisiones del lenguaje conducen, por otra parte, este movimiento a zonas inciertas, en una especie de no man's land, en los confines de lo jurídico y de lo político. Con el término "salvajes" no sólo hemos de referirnos a delincuentes; las "sanciones" no son infracciones menores y, por lo que respecta a los "errores", el término es, por lo común, las más de las veces reservado a los policías sin entrar a considerar para nada los errores judiciales, universitarios o periodísticos. No hemos de olvidar la ola de expresiones nuevas, en ocasiones tan perniciosas que nos guardamos de definirlas de un lado y otro de la barrera que separa al permiso del defendido, lo que contribuye a desestabilizar la protección, no obstante indispensable, de las libertades.

Alimentando, fortaleciendo el movimiento, ampliando de forma creciente la ideología con ilimitada ambición, los Derechos Humanos se perfilan como el signo de nuestro tiempo. Esto tiene lugar curiosamente sin que nos cuidemos de ello, ya que es una iniciativa individualista y subjetivista la que se desarrolla a continuación. Demasiados grandes espíritus han creído y han querido hacer de ello un motor de progreso, mientras que los escépticos han guardado a menudo un silencio prudente, por miedo a aparecer política y jurídicamente incorrectos. Poco importa si esta otra letanía ha podido conducirnos a una ideología de tipo mundialista, imperialista y, paradójicamente, neocolonialista. Poco importa si no es la religión de los Derechos 
Humanos la que ha emancipado África, dislocado la Unión soviética, derrotado al nazismo y al comunismo. Contentémonos con las adecuadas críticas que se le dirigen a la teoría de los Derechos Humanos por grandes espíritus como Kant, Hegel, Marx, Nietzsche y otros muchos más.

Ahora bien, vamos a contentarnos aquí con una observación de orden geológico. A los derechos-libertades de 1789 se superponen a partir de 1848 los derechos-principios, y otros muchos más a continuación, que atestiguan el rechazo del Estado liberal por el Welfare State. Se va sucediendo así la historia del liberalismo, del socialismo, del neo-liberalismo, del neo-socialismo hasta llegar al final al gran taponamiento operado a fuerza de declaraciones, de pactos, de convenciones. Este todo se ordena en base a una doble función, simbólica e histórica, revelada de forma pertinente por Raymond Aron con ocasión del XX aniversario de la Declaración universal de Derechos Humanos de 1948. Esta Declaración —escribe este autor- "critica la sociedad moderna en nombre de los ideales que ésta se ha dado a sí misma. Según el pensamiento sociológico, toda filosofía de Derecho Natural expresa y niega al mismo tiempo la sociedad de la que emana. Ésta coge prestado sus valores y al mismo tiempo le reprocha haberlos traicionado"4.

De ahí proviene una ambigüedad y una ambivalencia paradójica que no puede parar de desarrollarse: el derecho a casarse vs. el derecho a establecer legalmente una unión libre (PACS), el derecho a abortar vs. los derechos de la infancia, el derecho a la igualdad vs. el derecho a la diferencia, el derecho al progreso pero también los "derechos adquiridos", el derecho a la confidencialidad vs. el derecho a la transparencia de información. Numerosos antagonismos nuevos que constituyen propiamente el signo de una sociedad esquizofrénica. Entonces, de nostalgia en nostalgia, llegamos a considerar que el humanismo —ateo o no- ya no es lo que era que, tratando de dar asistencia a todo el mundo, terminamos por no ayudar a nadie y, en

${ }^{4}$ Aron, Raymond, "Pensée sociologique et droits de l'homme", en Etudes Politiques, 1972, p. 233. 
definitiva, que un "angelismo exterminador" (Alain-Gérard Slama) favorece un "imperio de Derecho" (Pierre Manent) que acaba por destruirlo en su función primordial: la coexistencia de las libertades. Dentro de este paroxismo internacional destaca el papel jugado, en enero de 2003, en el seno de la presidencia de la 59 sesión de la Comisión de Derechos Humanos de Naciones Unidas, la embajadora de Libia, Najat Al-Ajjaji, quien, respondiendo a todos aquellos que objetaban a su país haber cometido de forma reiterada flagrantes violaciones de los Derechos Humanos, afirmaba lo siguiente: "Me opongo completamente a tales afirmaciones. Puede haber a veces en Libia policías que dan bofetones a los detenidos en las comisarías... Ningún país es completamente inocente, pero repito, no hay una violación sistemática de los Derechos Humanos en Libia”.

\section{LA LEGALIDAD Y LA LEGITIMIDAD DE LO POLÍTICO}

Un reflujo de lo jurídico - o mejor dicho, un retorno al gusto de lo jurídico - probablemente aseguraría una de las más deseables adecuaciones. ¿Significaría esto que otorgaríamos a la política - entendida en el sentido moderno del término y no en el sentido clásico- el poder de abonar de nuevo el terreno abandonado? En absoluto, pues incluso en la posición positivista de Kojève, la política no se entiende sin hacer referencia necesaria a los valores y ésta ha de ser tomada en consideración a partir del Derecho en potencia, llamado a ser el Derecho en acto. Guiados por el mismo espíritu, algunos autores llegan a analizar la "autonomía de lo político"5.

El movimiento kojeviano se manifiesta ahora con toda claridad. Si un Derecho justo, pero en potencia, es oportunamente invocado, una fuerza inherente a la Idea de Justicia privará al Derecho positivo de la Autoridad que le es propia y necesaria para poder mantenerse con carácter duradero y favorecerá, de este modo, la plena realización

${ }^{5}$ Ellul, JACques, Lillusion politique, París, 1965. 
de la Idea de Justicia por el Derecho. En otras palabras, la transcendencia en el Derecho no es eliminada o, lo que es lo mismo, allí donde el Derecho y la Política tanto se acercan como se alejan el uno de la otra, el debate fundamental es planteado en términos de legitimidad, ya se trate de Derecho, de Filosofía o de Teología.

Legalidad y legitimidad, el debate se pierde en la noche de los tiempos ya que a través de ellas se manifiesta en Derecho la presencia de lo sagrado. En la historia moderna francesa, el concepto de legitimidad política toma cuerpo en el siglo XVI con Théodore de Béze y los seguidores al Monarca. El magistrado ostenta el poder de condenar según la ley divina, pero a condición de no alejarse en sus resoluciones de la piedad y de la caridad. Esto último explicaría la teoría del tiranicida: un príncipe legítimo, quien recibe su poder de Dios, puede convertirse en un tirano de no respetar las obligaciones que pesan sobre todo buen magistrado. En ese supuesto, la parte más santa del pueblo dispone de un derecho a su favor en contra del tirano, este derecho de resistencia puede llegar incluso hasta el regicidio. Durante largo tiempo, la historia de la legitimidad ha estado indisociablemente unida a la de la Monarquía francesa, ya que se trataba fundamentalmente de saber quién debería reinar en el Reino de Francia. Juana de Arco, en nombre del Señor, toma partido por el Rey legítimo contra el "vergonzoso Tratado de Troyes" (1420) — que había sido jurado, no obstante, sobre la Biblia- y proclama Rey a Carlos VII en Reims. Más tarde, durante las Guerras de religión, la invocación de las Leyes Fundamentales del Reino consagra la idea de considerar tirano y no Rey a todo monarca de Francia que sacrificara a su reino. Y cuando, a comienzos del S. VIII, el Tratado de Utrecht (1713) pusiera fin a la Guerra de Sucesión en España exigiendo renunciar al trono de Francia al Duque de Anjou y a su descendencia, este tratado fue considerado, en términos de legitimidad, contrario a las Leyes Fundamentales del Reino ya que, en su calidad estatutaria y no hereditaria, ningún monarca podía renunciar a la Corona, con más razón todavía cuando se tratase de sus descendientes. 
Mientras que la autoridad del Rey deriva su fuerza de Dios, la Filosofía des Lumières desplazó el lugar ocupado por la legitimidad política, que encontraría en lo sucesivo su fundamento en la voluntad de los ciudadanos. No obstante, resulta significativo que a lo largo de las numerosas vicisitudes que se han ido sucediendo durante siglos, se haya mantenido firmemente el recurso al concepto fundamental de legitimidad. La Historia nos da muestras constantes de cómo, en periodos de graves crisis - guerras exteriores o guerras civiles, revoluciones y revueltas sociales-, las exigencias sociales no se satisfacen siguiendo formas legales y cómo éstas encuentran en la disociación de la legalidad y la legitimidad el medio de acompasar a la vez al Derecho y a la política.

Todo ello explica el por qué cada vez que se producen crisis importantes, podemos observar un rechazo de la legalidad habitual, de la legalidad normal: circunstancias excepcionales, potestades excepcionales para hacer frente a las crisis, estado de urgencia, estado de sitio, etc., en definitiva, el Estado de excepción. Las medidas que acompañan a estas situaciones excepcionales son precisamente fruto de la política y no pueden ser comprendidas que dentro del ámbito propio de la política. Girogio Agamben lo ha expresado de forma excelente (Le Monde, 12 de diciembre 2002): “(...) se trata de medidas jurídicas que no pueden ser entendidas desde un punto de vista jurídico... El Estado de excepción se presenta (...) como la forma legal de aquello que no puede tener forma legal. La excepción soberana es el dispositivo original a través del cual el Derecho regula la vida con el objeto de incluirlo en el propio gesto donde éste suspende su ejercicio". En las circunstancias que siguieron a los atentados terroristas perpetrados el 11 de septiembre en Nueva York, la military order del Presidente Bush, con fecha de 26 de octubre de 2001, ha venido a ilustrar plenamente la existencia de medidas de crisis particulares. Esto último no significa que el Estado de excepción se confunda con un puesto de anarquía, al contrario. Más bien hemos de decir que, en comparación con el régimen ordinario, se ha de superar aquí la oposición ha- 
bitual que existe entre un estado de completa anarquía y un estado de plenitud del Derecho, ambos coincidentes con la totalidad de lo real.

No podemos eludir el debate filosófico de trasfondo que nace de una confusión, demasiado frecuente, entre legalidad y legitimidad. Más allá de ser una mera referencia ideológica, especialmente ilustrada en una determinada época por la persistencia del legitimismo y por la vigencia recurrente de los legitimistas, la legitimidad se constituye como algo inherente a la racionalización del Estado moderno bajo la influencia del liberalismo y del constitucionalismo. En estas condiciones, resulta ser comprensible que se considere como legítimo el régimen legal, es decir, aquel régimen en el que la autoridad se ejerce en virtud de leyes. "Existe una continuidad de la legalidad más allá de la discontinuidad de la legitimidad, es decir, que la misma sobrevive a las luchas por el poder y entre poderes" 6 . Y refiriéndose a Guglielmo Ferrero, Julian Freund atribuye a la voluntad expresa de este autor el llamar nuevamente la atención sobre la importancia de la "noción de legitimidad y de los principios de legitimidad entre los que la lucha constituye a sus ojos el fondo invisible de la Histo-

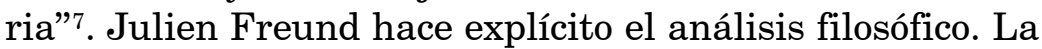
legitimidad "consiste en el consentimiento durable y casi unánime que los miembros y las capas sociales acuerdan a un tipo de jerarquía y a una clase dirigente con vistas a poder regular los problemas interiores por otras vías diferentes de la violencia y del miedo que le acompaña"8. "Puede ocurrir que un país soporte momentáneamente una autoridad excepcional durante un periodo de crisis y que en ocasiones lo aclame; pero, no es menos cierto que sólo la duración determina la legitimidad. Parece ser que ésta se fundamenta menos en las relaciones directas entre los gobernantes y los administrados que en el crédito que las diversas capas y clases sociales otorgan a la clase diri-

${ }^{6}$ Freund, Julian, Lessence du politique, París, 1965, p. 259.

7 V. Ferrero, G., Pouvoir, Les génies invisibles de la cité, op. cit.

${ }^{8}$ Freund, Julian, Ibíd., p. 260. 
gente. Así, pues, la legitimidad es esencialmente un fenómeno político y no jurídico que no deja reglamentar más que el propio poder que le sirve de cimiento" 9 .

Los tiempos turbulentos en los que vivió Kojève ilustran esta disociación -inmediata o progresiva- de la legalidad y de la legitimidad. No obstante, también se han de tener en consideración los precedentes históricos que les antecedieron. Ese es el caso concreto de la Carta de 1814, que expresamente disponía en su artículo 68: "El Código civil y las leyes actualmente existentes que no sean contrarias a la presente Carta permanecen en vigor hasta que sean legalmente derogadas". De este modo se manifestaba plenamente, a pesar de los cambios de régimen político, el principio de la continuidad del Derecho ${ }^{10}$. Ciento treinta años más tarde, tras la Liberación de Francia del régimen nazi, se planteó un problema similar, con la salvedad que aquí la Ordenanza de 9 de agosto de 1944 sobre el retorno a la legalidad republicana ha mantenido un principio de discontinuidad del Derecho considerando inexistente los textos jurídico-legislativos promulgados por el gobierno de Vichy. ¿Esto último se debe a que el régimen de Vichy era, en su propio fundamento, inconstitucional y contrario a la legalidad interna? O más bien, ¿es debido a que, desde el punto de vista del Derecho internacional, el régimen de Vichy era necesariamente el esclavo del invasor?

A partir de este aspecto particular, tal y como observa Jean Carbonnier, "hay que introducir otra idea que, a pesar de no figurar expresamente en la ordenanza, la penetra y la domina: la idea de resistencia"11. Esta idea confiere entonces "a la restauración legislativa de 1944 una fisionomía absolutamente original". En virtud de esta idea, verdadera o falsa, y sin embargo incorporada al Derecho Público francés, se admite que, en los años 1940-1944, el

9 Freund, Julian, Ibíd., p. 261.

${ }^{10}$ Liet-Veaux, G., La continuité du droit interne: essai d'une théorie juridique des révolutions, Tesis Doctoral, París, 1942.

11 V. CaRbonnier, Jean, Note Dalloz, 1946, p. 321, respecto a dos decisiones de 16 de julio y de 18 de diciembre de 1945 de la Sala de lo civil de la Cour de cassation. 
Derecho no ha dejado de coexistir con el hecho resistiéndolo; los ciudadanos tenían el deber -así como también el deber de cumplirlo ya que cumplían con ello a menudode no obedecer a las órdenes de la autoridad usurpada, que se acompañaban lo antes posible, como si de su propia sombra se tratara, de un contra-orden virtual de la autoridad legítima ${ }^{12}$ (J. Carbonnier, ibíd.). De esta forma — que resulta ser cuanto menos intelectualmente audaz-, tras la Liberación se podría reconstruir una legalidad continua. De fuerza se ha reconocer que, durante el periodo de la ocupación nazi, esta hábil explicación podía ser, de hecho, mucho más problemática.

Es a uno de esos grandes espíritus que seguirían las enseñanzas de Kojève en París, el Padre Gaston Fessard, a quien le corresponderá prolongar y profundizar en términos teológicos las reflexiones que habían sido desarrolladas, en un primer momento, en Derecho y Filosofía. Sus escritos y testimonios correspondientes a los periodos de la Ocupación y posterior Liberación fueron publicados con fortuna - republicados, para algunos-. Así, en su Diario de la conciencia francesa 1940-1944 ${ }^{13}$, Gaston Fessard formula las cuestiones centrales. Los franceses, ¿tenían que obedecer las órdenes de Vichy? En suma, ¿este gobierno era legítimo? Este autor considera que en el espíritu general de los franceses de la época reinaba una obsesión: ¿la unidad nacional resistiría a la guerra franco-francesa?

Desde el comienzo de la Ocupación, Gaston Fessard forjó el concepto del "Príncipe-esclavo", en este caso, el régimen de Vichy. Un panfleto que circuló en tiempos la clandestinidad después de 1942 ilustra esta idea con una interrogación significativa: ¿qué es un gobierno "legítimo"? La respuesta se forja a partir del "Bien común": es legitímo el gobierno en el que el Príncipe, emplazado en la cúspide del Estado, posee al mismo tiempo las "luces" necesarias para discernir dónde se encuentra el Bien común del

12 Carbonnier, Jean, Ibíd.

13 Fessard, Gaston, Journal de la consciente française 1940-1944, París, Ed. Pion, 2001. 
pueblo y la fuerza indispensable para dirigir las voluntades de todos hacia este fin único.

El Bien común de una Nación se descompone, a juicio de Fessard, en tres elementos. El primero corresponde al cuerpo y consiste en la existencia y la seguridad de los ciudadanos. El segundo, correspondiente al alma, está constituido por los valores o ideales que, para estos ciudadanos, están conformados por su razón de vivir en un grupo. El último de estos elementos, que responde a la composición humana y que se sitúa entre los otros dos - el superior y el inferior- abarcando ambos, es un orden de Derecho. Ahora bien, en el caso concreto del régimen de Vichy, dicho orden había nacido porque se accedidó a ratificar el armisticio de 1940 y tan sólo subsistía en la medida en que así lo dispuso y quería el vencedor. La complejidad de esta última situación lleva a Gaston Fessard a mantener una distinción en términos de límites o de relaciones. Por un lado, con la finalidad principal de restaurar el país y así evitarle grandes males, el régimen de Vichy no resultaba ser ilegítimo si tenemos únicamente en consideración su situación respecto a ilegitimidad del poder del invasor. Pero, por otro lado, dicho régimen no disponía de la confianza que se le atribuye a una autoridad "establecida durante un largo tiempo y reconocida unánimemente por la adhesión del pueblo". Desde esta última perspectiva, en relación con una autoridad legítima en el sentido tradicional del término, dicho régimen no era legítimo.

En una demostración que bien podría recordarnos a la comparación que existe en Derecho Internacional Público entre el reconocimiento de facto y el reconocimiento de jure de los Estados extranjeros, Gaston Fessard distingue dos niveles diferentes. A su juicio, existe una legitimidad de hecho, en sentido directo, que es admitida en razón de la existencia de lo justo y de lo legal por oposición a lo que es injusto y lo que es ilegal. A un nivel todavía superior, accedemos a la llamada legitimidad de derecho, en sentido reflejo, la cual se orienta más en términos de reconocimiento de autenticidad. Entre estos dos niveles, no hay situación posible de ruptura, sino un vínculo, un lugar de 
paso en un sentido o en otro. La plenitud de la legitimidad supone que lo que es justo y legal sea también reconocido como auténtico. Pero, también puede no serlo —estima Gaston Fessard-, sin que por tanto caiga en la injusticia y en la ilegitimidad. En definitiva, esta es otra manera de tratar el derecho en potencia y el derecho en acto.

Todo este razonamiento no resulta en absoluto sorprendente si tenemos de nuevo en consideración la influencia de Kojève y una comprensión innata de la legitimidad de lo político, a pesar de las ausencias de la legalidad. Esto explica por qué el respeto obstinado de determinados grandes espíritus a la legalidad en situaciones de crisis puede ser fácilmente objeto de mofa, si no incluso llegar a parecer simplemente ridículo. Veamos a continuación dos ejemplos, ambos relativos a eventos acontecidos en un mismo año, en 1944.

El primero de dichos ejemplos se refiere a Saint-John Perse, o más concretamente Alexis Léger, cuya influencia en Francia ha sido considerable durante el periodo de entreguerras bajo el signo del Derecho de los Tratados, abogando en este aspecto particular por un sentido del Derecho de lo más ilusorio. De su juventud y de su etapa de estudiante de Derecho, Alexis Léger siempre conservó "el gusto por las relaciones jurídicas bien reguladas entre los hombres, entre los hombres y las cosas"14. Esto último explicaría este intercambio de alianzas mediante las cuales se creyó poder conjurar el retorno de las guerras, la revancha de los alemanes, el peligro comunista. Con demasiada rapidez se descuidó la fragilidad de las construcciones jurídicas nacidas bajo el auspicio de la Sociedad de Naciones.

Años más tarde, sorprende comprobar que nuestro autor no había comprendido ni olvidado nada. En una carta no apócrifa - ya que no había sido escrita por sí mismo a los fines de vanagloriar su propia figura-, con fecha de 31 de enero de 1944, Alexis Léger escribe al Presidente Roosevelt lo siguiente:

14 Sacotte, Mkeille, Saint-John Perse, Ed. Les dossiers Belfond, París, 1991, p. 92. 
"Se aproxima la hora en la que las reglas militares, en la preparación de la invasión, puedan imponer a los aliados las más altas responsabilidades morales ante el pueblo francés. Para poder determinar la modalidad a la que se ha de recurrir para la administración provisional de los territorios franceses liberados, importa que el papel que le corresponde por Derecho al elemento francés sea siempre plenamente compatible con el respeto de la Ley constitucional de 1872 sobre la que el propio pueblo francés ha fundado sus garantías democráticas (Loi imposant la convocation des Conseils Généraux à la libération du territoire). En efecto, como en Derecho, esta Ley fundamental satisface las necesidades de la situación actual. Ningún organismo de administración provisional francesa no sabría renunciar a su aplicación sin romper así con la legalidad francesa y sin incurrir en un abuso de poder frente a una voluntad nacional todavía difícil de identificar. Ningún gobierno aliado no sabría prestarse a ello sin soportar él mismo esta doble responsabilidad política y moral"15.

Sean cuales fueren las causas de dicha opinión - animosidad personal frente al General de Gaulle, rencor de un exiliado no resistente, indiferencia ante la resistencia francesa...-, es evidente que la evocación de una legalidad no esperada, fundada sobre un texto polvoriento que no tenía nada que ver con la liberación de Europa, resulta ser significativa de un legalismo anacrónico, dañino y, dicho de paso, ilegítimo; cuanto más cuando los Consejos generales a los que alude la Ley constitucional de 1872 a menudo se comprometieron con la política de Vichy.

El segundo ejemplo que queremos sacar a colación es la figura de un jurista excepcional, uno de los nombres más importantes en la ciencia jurídica francófona del S. XX, Georges Ripert. Efímero Ministro de Pétain en 1940, Decano de la Facultad de Derecho de París bajo la ocupación nazi de Francia, Ripert creía estar a salvo de posibles persecuciones y venganzas puesto que consideraba que para detenerlo y perseguirlo en justicia era necesario que se

${ }^{15}$ LÉGer, AleXis, Euvres complètes, La Pléiade, París, 1972, p. 619. 
diera un texto legislativo retroactivo. En buena hora... Georges Ripert, directamente expuesto a las represalias que siguieron a la Liberación, se encontraría inesperadamente en Drancy muy bien acompañado por sus compañeros de aventura Sacha Guitry, Bernard Fay, Fabre-Luce, Berthelot, Abel Hermant, así como un "maestro-vidriero".

Veamos a continuación el curso de una entrevista solicitada a Ripert por sus compañeros el 7 de septiembre de 1944, reproducida por Sacha Guitry.

"Vd. que lo sabe todo, Sr. Decano, díganos cuáles son nuestros derechos. ¿Por qué nos han detenido como lo han hecho? ... ¿Pueden mantenernos en prisión durante más tiempo? ... ¿Podemos exigirles que nos interroguen? ...

$Y$ de repente sentimos como si la verdad surgiera de esa fuente de sabiduría que era la boca de tan docto viejecito.

- Señores míos, actualmente estamos a merced de quienes se han apoderado de las palancas de cambio. No sé lo que el futuro inmediato nos reserva y, sin embargo, no creo equivocarme cuando pienso que al final siempre nos quedará la posibilidad de demandar al Ministro del Interior. Pero, escúchenme bien...

Y para entender sus palabras mejor, todos nos desplazamos de nuestros sitios

¿Pero?

Pero... ide demandarlo intuitu personae!

Fabre-Luce, Bernard Fay, Albert Hermant y Berthelot, aprobadores, asentían con la cabeza, mientras que el maestro-vidriero y yo nos mirábamos por el rabillo del ojo, confundidos $y$, por la primera vez, molestos de apenas haber profundizado en el estudio de las lenguas muertas" 16 .

¿No eran las circunstancias en el año 1944 más propicias que nunca para fundamentar precisamente una legitimidad plena de lo político, ante la cual una legalidad muerta hubiese perdido todo valor?

16 Guitry, Sacha, Soixante jours de prison in Cinquante ans d'occupation, Ed. Omnibus, París, p. 983. 